\title{
11 Migrants, ethnic minorities and mobility poverty
}

\author{
Patrick van Egmond, Tobias Kuttler \\ and Joanne Wirtz
}

\begin{abstract}
Very few studies in Europe have investigated the mobility needs and travel patterns of migrants or have included ethnic perspectives. Apart from generally having less access to cars, barriers in accessing public transport can also be identified. Among these barriers are language barriers, availability and accessibility issues, the cost of public transportation and racial and religious discrimination.

This chapter investigates the existing literature on mobility patterns and problems of migrants in Europe and beyond. In a second step, previous insights are complemented by findings from the authors' own research. The HiReach project investigated the mobility needs and problems of refugees in Luxembourg and Germany. This research provides a rare insight into the mobility poverty experiences of migrants who recently arrived in Europe.

This chapter will outline the mobility challenges first and will then highlight some approaches to solutions in the final part.
\end{abstract}

\section{Migrants, ethnic minorities and mobility}

The travel behaviour of migrants in the environment of their destination country is a neglected area of statistical information and research. There is little knowledge regarding the travel behaviour and attitudes of immigrants in Europe towards different travel modes, due to scarce data and information. Trying to grapple with the research gap, this chapter will provide an insight into the number of migrants and ethnic minorities presently residing in the EU, their socio-economic situation, the specific needs and socio-cultural characteristics of migrants and ethnic minorities in relation to mobility and transport. To further close the research gap, links will be drawn from existing literature to the results from two case studies in Germany and Luxembourg in the HiReach project. ${ }^{1}$ It will show how a mismatch between these needs and the present mobility offer might lead to an increased risk of exclusion. A number of solutions are discussed, such as fare reduction and familiarisation with alternative forms of mobility, such as cycling. Finally, we will look at changing perceptions and transportation usage among migrant and ethnic minorities in order to estimate the impact of digitisation and the debate on climate change. 


\section{Migrants and ethnic minorities in the EU}

Migration is presently much debated in the European Union. This specifically focuses on migration from the Middle East and the African continent. For the EU, a migrant person is "a broader-term of an immigrant and emigrant that refers to a person who leaves from one country or region to settle in another, often in search of a better life" (European Commission 2016). The EU's official position towards migrants is that they represent an important part of the development of European societies, both in economic, social and cultural perspectives. Meanwhile, there is fear from part of the population about the effects of migration, specifically from non-EU countries, on their society and living conditions.

In 2017, 2.4 million immigrants entered the EU from non-EU countries. This brought the number of non-EU citizens up to 22.3 million persons (4.4\% of the 512.4 million people living in the EU). The EU Member States granted citizenship to 825 thousand persons in 2017 (Figure 11.1).

Securing successful acclimatisation for migrants at their places of destination is for the benefit of both migrant and domestic societies, and maximises the positive effects of legal immigration to EU development. It is nevertheless clear that in many situations migrants are vulnerable populations, due to a myriad of possible reasons.

Some of the migrants can also be included in the definition of ethnic minority, even if most of the ethnic minorities in most European Member States have been part of societies for more than a generation, sometimes even for several generations.

Ethnic minorities represent a group for whom social and economic exclusion remain an everyday challenge in Europe today. Cultural and ethnic

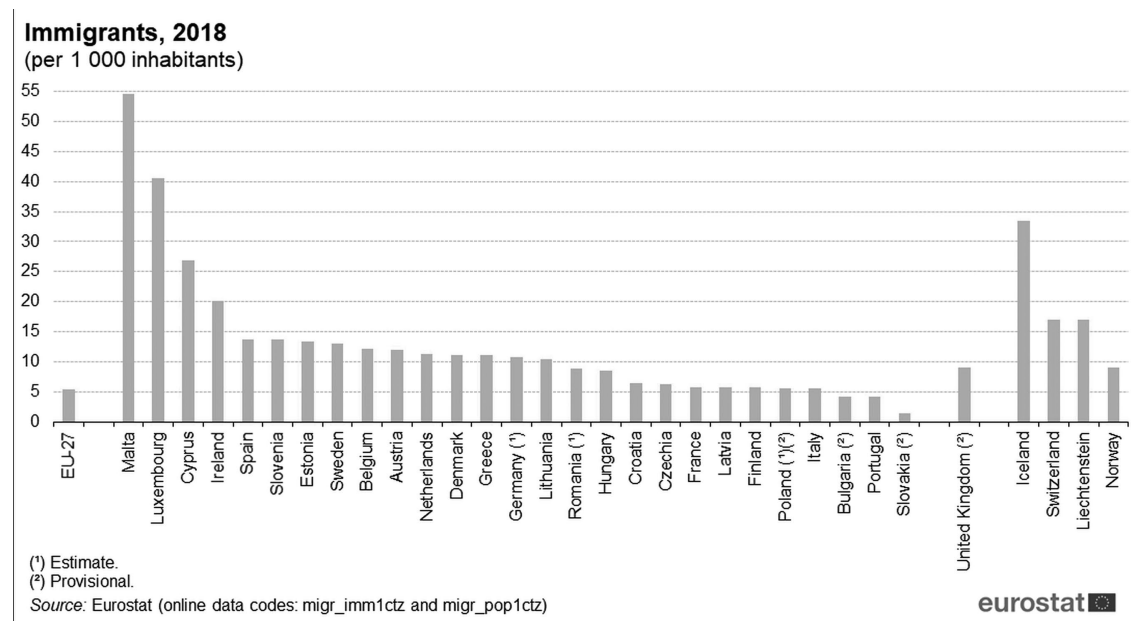

Figure 11.1 Share of Immigrants in EU Member States, 2018.

Source: Eurostat 2019. 
backgrounds shape the challenging differences between ethnic minorities and majority populations. These differences are often also reflected on the labour market (unemployment, underemployment and substandard remuneration), uneven access to health care and social services. Especially relevant are the connections between appropriate quality of life, prosperity and social cohesion and the absence of significant labour market segmentation (Kahanec et al. 2010).

Figure 11.2 shows that in many countries Europeans represented almost half of all the foreign-born people who lived in an EU Member State. Some European cities account for very large proportions of migrant or ethnic minority populations. For example, London has an estimated $40 \%$ "Black, Asian and minority ethnic (BAME)" population (Transport for London 2014), while Berlin has an estimated 18\% non-European population. Interestingly, while some regions attract most of their migrants from a narrow range of countries, others are extremely diverse, drawing migrants from around the world. This is particularly true for some of Europe's largest cities and capital cities, for example, the regions of Hamburg, Munich, Paris, Amsterdam, Stockholm and London. Geographic proximity, ex-colonial links, common languages and cultural ties play an important role in determining the destinations favoured by migrants (Tsang and Rohr 2011).

Analysing recent Eurostat statistics regarding migrants, it is possible to characterise them properly. For example, men represented $54 \%$ of the immigrants to the EU Member States in 2018. This share was the highest in Croatia (75\%) and the lowest in Portugal (53\%) (Eurostat 2020).

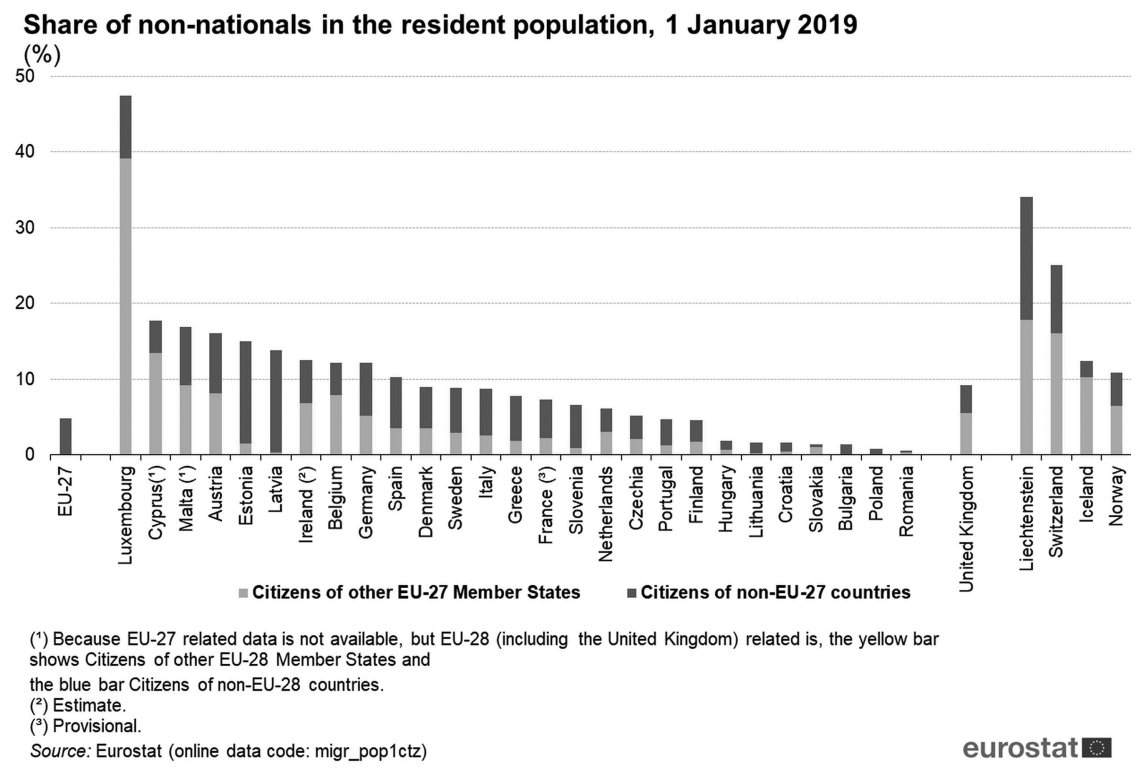

Figure 11.2 Share of non-nationals in the resident population, 1 January 2019. Source: Eurostat 2019. 


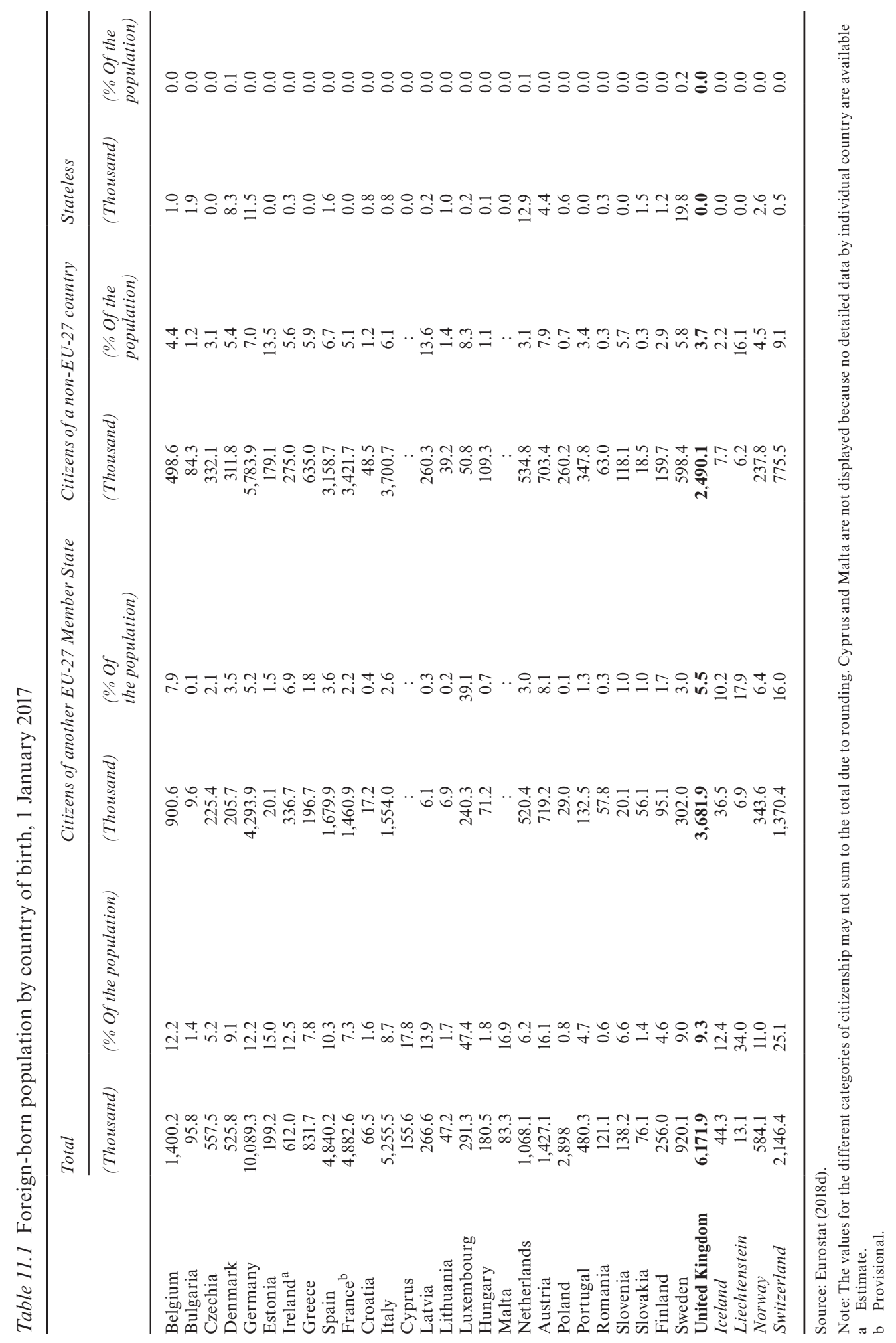


Regarding the age of immigrants, they were considerably younger (with a median age of 27.9 years in 2011) than the total population already residing in their country of destination (with a median age of 42.9 years) (Eurostat 2016) (Figure 11.3).

Being part of a migrant or minority ethnic group is likely to increase the risks of marginalisation and poverty, namely due to factors such as discrimination, racism and cultural and language problems. These (especially if combined) reduce access to good-quality jobs and education and increase the likelihood of living in deprived areas. Within these groups, women are particularly at risk.

Data from an EU-28 survey in 2017 shows that one in four (24\%) respondents felt discriminated against because of their ethnic or immigrant background in the 12 months preceding the survey. The highest rates of discrimination based on ethnic or immigrant background are observed in the area of employment and when accessing public and private services $(\mathrm{Eu}-$ ropean Union Agency for Fundamental Rights 2017), namely health, education and transportation.

\section{Mobility behaviour and mobility-related disadvantages of migrants and ethnic minorities}

As mentioned earlier, very few studies in Europe have investigated the mobility needs and travel patterns of migrants or have included ethnic perspectives in their studies. Therefore, it is necessary to expand the scope and also include studies from other parts of the world.

Comprehensive studies on the relationships between travel behaviour and immigrant status focusing on the distinctive travel patterns of immigrants have been conducted in the United States (see e.g. Myers 1997; Rosenbloom and Fielding 1998; Deakin et al. 2002; Purvis 2003; Casas et al. 2004; Handy and Tal 2005; Chatman and Klein 2009). These studies suggest that in the first five to ten years of living in the United States, the travel behaviour of immigrants is different from the behaviour of citizens born in the United States, but immigrants often assimilate after just five years. Also, usage of public transportation differs among immigrant groups, regardless of the amount of time they had been residing in the United States. Although there is usually a preference for private modes of transport such as cars, (Blumenberg 2008; Lovejoy and Handy 2008), some groups, e.g. Latino communities, are more open to using collective modes of transport (Douma 2004; Valenzuela et al. 2005). This includes car-pooling, sharing rides and borrowing cars in social networks, as identified by Lovejoy and Handy (2011) in the case of Mexican immigrants in California. Tal and Handy (2010) suggest that mode preferences stem partially from attitudes based on previous experiences in the country of origin and that different travel behaviours are also a result of the social segregation of immigrants. The spatial location of residence and residential choices also have an impact on commuting behaviour, as Beckman and Goulias (2008) point out for the case of California. 


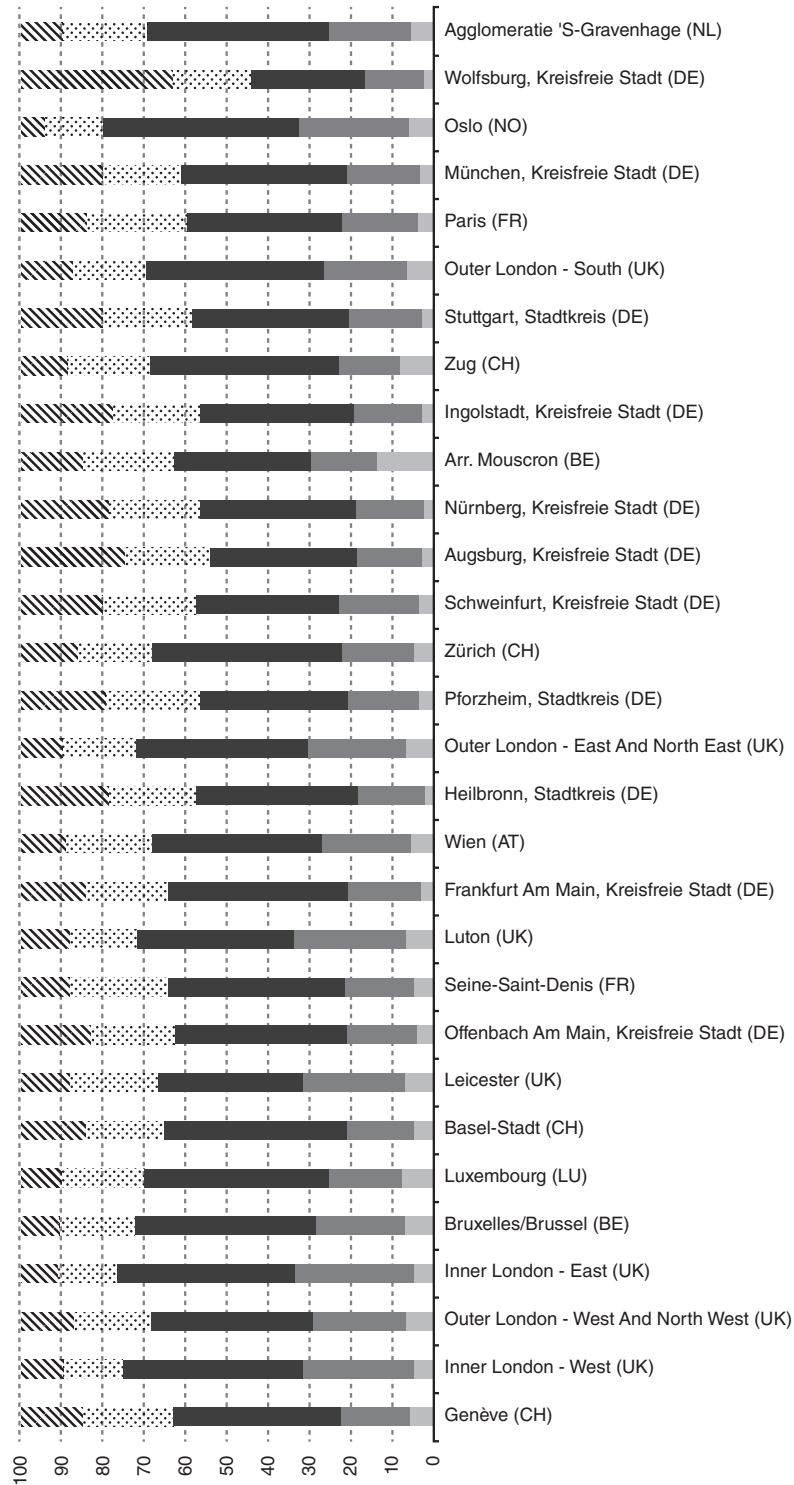


For two metropolitan areas in Australia, Klocker et al. (2015) observed below-average rates of car ownership and use amongst ethnic minorities and migrants. However, they found that these are not the result of socio-economic deprivation, but rather a result of cultural factors and experiences of transport in countries of origin as well as the choices for residential location.

Insights into travel behaviour and mode choice of different ethnic minorities and migrant groups in Europe are largely absent. For the United Kingdom, Rajé (2004), referring to other older small-scale studies, summarised attitudes towards the different modes of transport of women in London. While all women felt unsafe walking at night, they would usually feel safe during the day. The transport usage of women differed substantially between women of Asian origin and those of Afro-Caribbean origin.

Several studies in Europe focussed on accessibility to public transport for migrant groups and ethnic minorities. These studies highlight that the availability of public transport at affordable fares has effects on employment opportunities and access to basic services. This is particularly relevant considering that migrant populations are more prone to low incomes and unemployment (Samek Lodovici and Torchio 2015). Apart from being more at risk of ill health, poverty and unemployment, ethnic minorities are more likely to live in deprived areas as well as in overcrowded or unpopular housing (Rajé 2017).

For groups at risk of social exclusion, remoteness can also have a significant impact on their quality of life, as they often do not have access to cars.

In relation to the use of public transport, the following barriers were identified in the "Together on the Move" project (Assum et al. 2011):2

- Language barriers;

- Availability and accessibility issues;

- Costs; and

- Racial and religious discrimination.

It has to be stated that, beyond low incomes and other barriers, there are also matters of racial and religious discrimination that have an effect on personal mobility and make the usage of (public) transportation an unfortunate experience. It was already found in earlier research that even migrants who were actually originally from middle to upper class environments in their country of birth were nevertheless experiencing social exclusion in their migration destination. Migrants of South Asian origin living in London reported that they are facing discrimination not only at their workplace but also while travelling on public transport. Living at the margins of society, they almost never leave the areas around their houses (Rutten and Verstappen 2014). Rajé (2004, 40) also reports from a study about the perception of crime and safety in London that black and minority ethnic communities exhibit higher levels of fear than non-minority groups, partially due to the higher levels of harassment they experience. 
Other forms of discrimination were reported from all over the United Kingdom, such as bullying of black school children, bus drivers not stopping for members of ethnic communities, attacks on black bus drivers, to name a few frequent incidents (Beuret et al. 2000, cited in Rajé 2004, 42-43). Negative perceptions of public transport can be partially traced back to experiences in the country of origin, as already highlighted above; Rajé $(2004,47)$, for instance, reports about negative attitudes of migrants from the West Indies in the United Kingdom, due to the dangerous circumstances and unreliability of public transport in Jamaica and other parts of the Caribbean.

The HiReach research also found that - in the case of Luxembourg young immigrants or ethnic minorities and immigrant women wearing headscarves often say that they are the first ones to be checked at inspections.

Given that these groups are highly dependent on public transport, but have difficulties in accessing those services that cater to their needs, it was brought up in the focus group discussion that there is the probability of switching to private second-hand vehicles at some point. However, these exhibit increased emissions and air pollution.

A particularly vulnerable group among ethnic minorities and migrant groups are the elderly. In the United Kingdom, access to cars is lower among the elderly, especially among communities of Asian origin, but they also have negative perceptions of public transport. Many elderly from ethnic minorities in the United Kingdom were unaware that they are entitled to travel allowance (Rajé 2004, 40-41).

Overall, the travel patterns of ethnic minorities and migrants are still poorly understood in Europe. In research projects, members of such groups are often hard to reach. Also, when there are consultations for specific transport development projects, members of ethnic communities may not participate because appropriate channels of communication between authorities and the communities are not in place and hence the members may not have heard about these plans (Rajé 2004, 81-82, 94-97, 2007, 67). Rajé also highlights the "experience gap" between the experiences of transport system users and the understandings of users' experiences held by planners and policy-makers. Besides gender bias, this can in particular be traced back to the ethnic composition of the transport planning profession (Rajé 2007, 52).

Fiona Rajé has criticised a lack of cultural awareness among transport professionals and has therefore called for a micro-understanding of the role of ethnicity in mobility patterns. Taking such perspectives into account, she argues that "complexities around journeying at every stage of the process" should be discussed in transport policy literature (Rajé 2004, 47). She highlights that when not aware of cultural specificities, the practices of social seclusions especially of women would not be taken into account. This has the effect that some dimensions between ethnicity, transport and social exclusion would remain hidden, for example that women rely on men or women of different ethnic groups to fulfil certain everyday tasks (Rajé 2004, 49-51, 64-67). 


\section{Mobility needs and the problems of refugees in Luxembourg and Germany}

During the course of the HiReach research, it became evident that migrants and ethnic minorities should not be treated as a homogeneous group. Many are well integrated in society as the result of having already been in their host country for a few years, different economic situations as well as their ability to adapt more quickly to the mobility and transport habits in the country. Mobility poverty among migrants and ethnic groups combines the difficulties of those newly arriving in a country with other aspects of vulnerability (e.g. old age, disability, low income).

The HiReach project investigated the particular mobility needs and problems of refugees in two regions of Luxembourg and Germany. The HiReach project therefore provides a rare insight into the experiences of mobility poverty of migrants who recently arrived in Europe. Besides material deprivation and language barriers, this study also took the living, employment and education situation of refugees into account. Specific attention was given to the mobility situation of women, since earlier work shows that having good access to public transport is very relevant for women (Uteng 2009).

HiReach research shows that newly arriving refugees are heavily reliant on public transport, which is costly for them if they have to pay for it themselves. For those having direct and convenient access to public transport, it is easier to find opportunities for employment, education and meeting friends.

The place of accommodation is in this regard essential and can have a significant effect on everyday mobility. Initial accommodation for refugees - that is provided by the state - is considered as a "lottery" from the viewpoint of the refugees. Such accommodation may be assigned in urban centres or in rural areas where there is less public transport connectivity. The personal situation and characteristics are usually not considered when accommodation is assigned to them and this potentially hinders them in their everyday life. When refugees need to find accommodation on the conventional housing market, they often face difficulties. In many urban areas in Germany, housing is so expensive that refugees are forced to live in areas less well served by public transport.

HiReach research suggests that refugees would use public transport more often, and would travel more overall, if they had a price-reduced monthly ticket. Especially for newcomers, a free ticket would significantly reduce their travel budget and, since expenses for mobility eat up a large part of their monthly budget, it would also ease their financial situation overall. Some cities in Germany have recognised this need, for example Berlin, where the "Welcome to Berlin" ticket is offered at a heavily subsidised rate. Luxembourg has made its whole public transport free of charge for all users.

However, refugees participating in the research indicated that they would be willing to pay for public transport if that would increase its availability 
and more efficiently meet their mobility needs. This confirms that mobility is only partly limited by financial constraints, especially when it comes to leisure trips. Interestingly, half of those who participated in the HiReach research stated that they would not walk or use their bikes less if they had a cheaper public transport ticket.

Earlier research shows similar challenges among non-EU migrants, independently of their year of arrival, socio-demographic characteristics or place of residence and work (Tsang and Rohr 2011).

A free or public transport fare at a reduced rate should be intelligently combined with good access to transport. For example, the HiReach focus groups discussed the case of the Stuttgart social ticket. This ticket offers a reduction of half the ticket price for monthly tickets for the inner zones, but, for monthly tickets over larger distances, the reduction is less than a third. Hence, in such a pricing structure, those who have to travel large distances for work or education, which is often the case for migrants and ethnic minorities, are more disadvantaged than those located in an urban area.

Nevertheless, it is clear and was also voiced that a social ticket is better than no fare reduction at all. It was confirmed that a monthly ticket at a reduced price would enable them to find a job or place of education more easily.

It became clear that for education (school, study, training) migrants and ethnic minorities have to travel long distances, but shopping, activities with children and other purposes are usually conducted within walking distance.

In relation to the purpose of travel, there were specific findings on the mobility problems of women refugees. Women have to travel longer distances than men, e.g. to attend a specialist doctor. The language problem seems to be more severe for women because some of them are illiterate and have difficulties in using a ticket machine. Women also travel more often with young children on public transport.

In general, for recently arrived refugees, it takes some time to understand the complex tariff and ticket system on public transport even if there are often local volunteers and the social service for refugees to support newcomers by explaining how the public transportation system works.

One finding not to be neglected was that refugees from African countries reported that they face discrimination on public transport. It seems that, especially when young African men are travelling in groups, they are suspicious to ticket inspectors and checked more often.

Riding a bicycle in particular, as with public transport, appears to be regarded as an inferior form of transport at least by certain immigrant groups. Cycling appears to be more appealing to locally born people than to immigrants, especially women (Samek Lodovici and Torchio 2015). Cycling is common among male refugees. In particular situations, e.g. when public transportation is not available on weekends or during the night/early/late hours, cycling is also used to travel between urban areas. Even though over half of refugee women know how to ride a bicycle, bike usage among these 
women is not common. The remaining women expressed that they would be eager to learn how to ride a bicycle.

Several newly arriving citizens have a driving licence or are undergoing driver training and exams. Nevertheless, car ownership is lower among immigrants, which can be suggested to be related to their less favourable economic conditions (Samek Lodovici and Torchio 2015) and they travel less in general. Trips are fewer and travel distances by car are shorter among immigrants than among the domestically born populations (Assum et al. 2011). Licence holding, car ownership and car use are not strictly related, namely because deciding to buy a car or to get a driving licence derives from individuals' needs, financial constraints and preferences (Tsang and Rohr 2011).

The differences in public transport access, cycling and car usage between migrants and those domestically born seem to be greater for women than for men and greater for newly arrived migrants than for migrants who have stayed longer in their new country. This confirms earlier work on this topic (Assum et al. 2011; Samek Lodovici and Torchio 2015).

It shows that pre-existing attitudes towards different modes combined with improved economic standards among immigrants over time leads to higher car access among immigrants and consequently to less sustainable travel (Assum et al. 2011). The HiReach work showed that, as a result of the present climate concerns and debate, this position is evolving. Climate change is not neglected within the groups of refugees and ethnic minorities. Specifically, the younger migrants in Luxembourg also expressed environmental concerns as a reason to use more sustainable modes of transport.

Specifically, cycling is seen more and more as a possible solution to their transport needs. Some refugees involved in the HiReach research did not know how to cycle, especially the elderly and women. On the other hand, access to a bicycle is usually available (i.e. their own bicycle or a public bicycle). It was pointed out that many newcomers are eager to learn how to ride a bicycle and that it is important to learn how to cycle in car traffic.

A cycling training programme such as Fietsmeesters in the Netherlands trains people how to ride a bicycle. It provides easier accessibility to transportation because of the minimal cost of cycling compared to other transport modes. Also, the maintenance cost of a bicycle is considered quite low. In Germany, the mobility of refugees is supported by local volunteer organisations collecting used bicycles among the residents of towns and villages. Members of the volunteer groups repair the bicycles and donate them to newly arriving refugees. Furthermore, some of these volunteer groups provide bicycle repair and maintenance facilities for refugees and train refugees to repair their bikes themselves (Figure 11.4).

As mentioned above, a number of participating women knew how to cycle. A Syrian participant mentioned that in Syria a lot of women know how to ride a bicycle, especially younger women from urban areas. A cycling programme for elderly people would be particularly interesting as a fun physical leisure activity (Figures 11.5 and 11.6). 


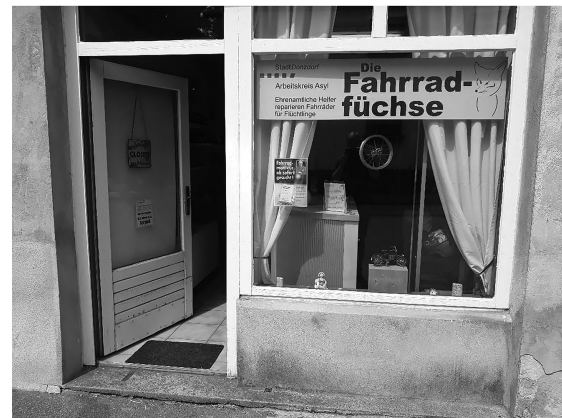

(a)

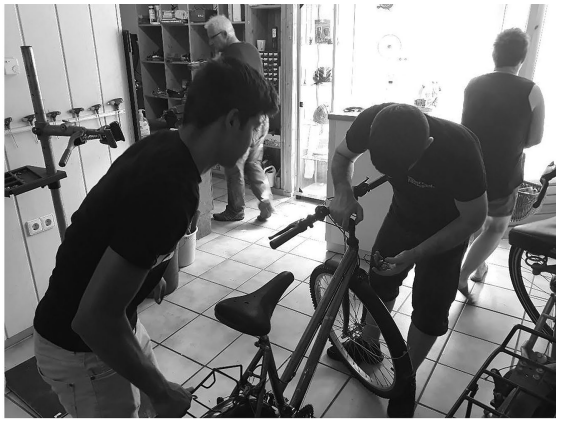

(b)

Figure 11.4 Die Fahrradfüchse ("bicycle foxes") is a volunteer organisation in the town of Donzdorf in southern Germany. With support from the municipality, it offers bicycle repair and maintenance facilities for refugees. These facilities are also open to other low-income persons in the region.

Source: Tobias Kuttler, TU Berlin.

(a)

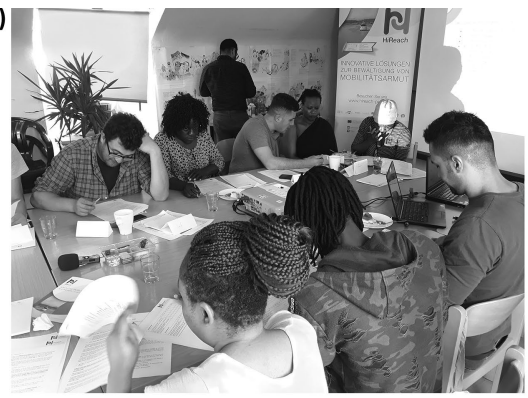

(c)

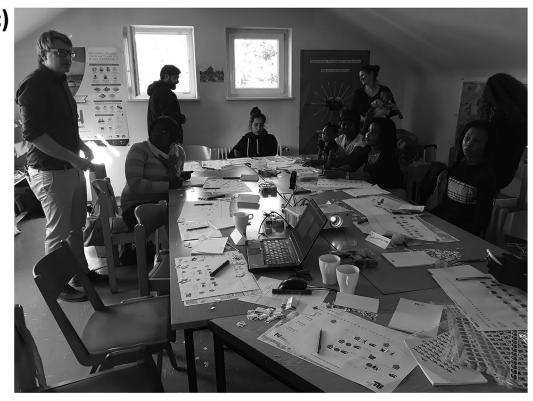

(e)

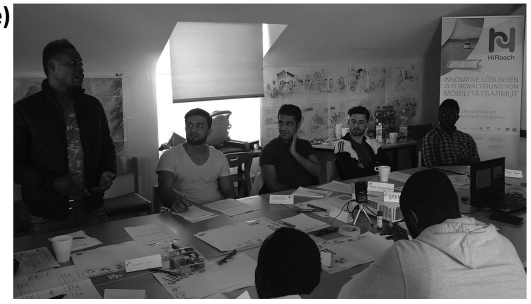

(b)

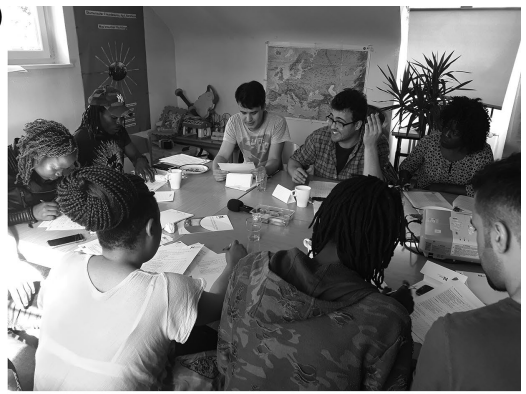

(d)

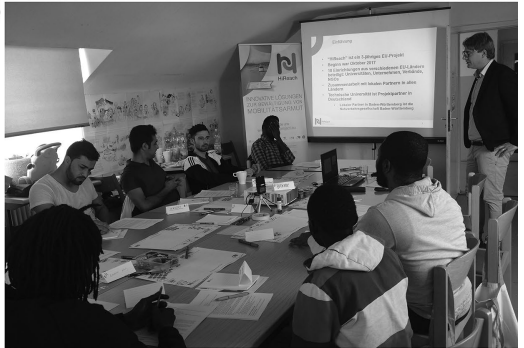

(f)

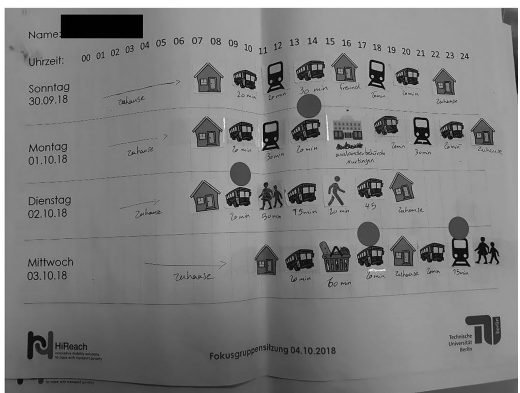

Figure 11.5 Focus group sessions with refugees in Esslingen (Neckar)/Germany. Sources: Tobias Kuttler, TU Berlin. 


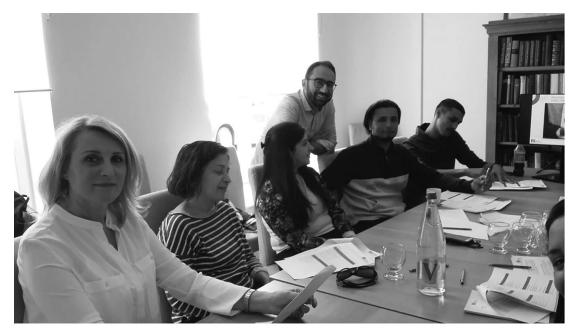

(a)

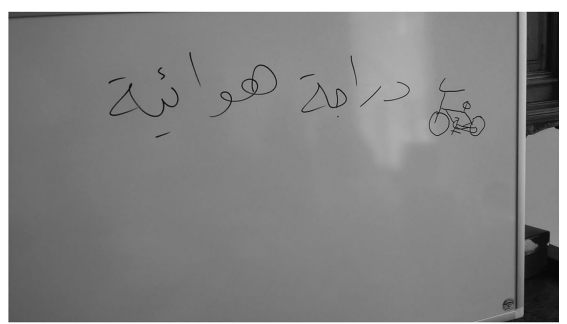

(b)

Figure 11.6 Focus group session with migrants and refugees in Luxembourg. Sources: Patrick van Egmond/LuxMobility, Luxembourg.

\section{Openness towards ICT-supported mobility solutions among refugees}

HiReach enabled an understanding of the effects of mobilities and related perceptions within groups of refugees and migrants to be provided as a result of the introduction of ICT and new forms of mobility.

The internet is a major source of information especially for newly arriving migrants and refugees. They are often frequent users of ICT. Furthermore, social media is vital to maintain connections with families and friends at their places of origin (see e.g. Charmakeh 2013; Harney 2013). Studies in Australia and New Zealand found that newly arriving refugees have largely positive perceptions of ICT, its usefulness and importance; they use ICT extensively for finding accommodation and jobs, being involved in new social connections and networks, and - finally - organising their daily mobility (Kabbar and Crump 2006; Felton 2015). However, the study also found that there are significant language, literacy and cultural barriers for many refugees when using ICT solutions (Alam and Imran 2015; Felton 2015).

ICT is particularly important for refugees in organising travel and navigating the city (Felton 2015). In a study about Syrian refugees in Germany, it was highlighted that smartphone usage helped refugees to overcome language barriers, especially when travelling in the city. Being able to travel, with the support of ICT, contributed to a sense of agency and well-being among refugees, thereby also enhancing perceptions of social inclusion (AbuJarour and Krasnova 2017).

In our own research, it was found that migrants had more mobility needs in terms of travel to the city centre for education and administration. Mobility needs also included seeing friends, personal appointments, education and sport. It showed that the newly arriving migrants seem to have fewer issues in fulfilling those needs as they were able to better understand the public transport network in comparison to the elderly resident population and older migrants. Younger migrants in particular are well acquainted 
with internet and smartphone applications and it is easy for them to find fares and information on public transport services including new forms of mobility (e.g. public bicycles). However, the HiReach work points out that newcomers are sometimes confused about the rules regarding tickets and that they had consequently been in trouble with ticket inspectors.

Also, all types of ride-sharing solutions seem to have a potential to reduce mobility poverty among migrants and ethnic minorities to a certain extent. First, as described earlier, due to the high perceived costs of travelling on public transportation, ride-sharing can be a cost-effective alternative. Second, many refugees need to travel at odd times (late evening, early morning, weekends) for their jobs or want to visit friends in other parts of the region where public transport connections are less frequent or cumbersome with many interchanges. Third, it became clear that refugees intensively use ride-sharing for long-distance trips, such as BlaBlaCar, hence they could easily relate to local ride-sharing solutions for local and regional travel. Finally, especially the younger migrants make intensive use of smartphones so that a smartphone-based ride-share solution would be less of an issue for them.

In the focus group sessions with refugees, a ride-sharing solution called "Fairfahrt" was discussed. Fairfahrt (fair-ride in German) is a ride-sharing platform organised in and around the small town of Romrod, located in the rural area of Hesse, Germany. ${ }^{3}$

Generally, the migrants participating in the focus group stated that local ride-sharing is a good idea and that it would be a way to use ride-sharing in the city and region. Most of the refugees already use BlaBlaCar, but services on this platform are usually not for short distance travel. A system like Fairfahrt would supplement public transport at times of low frequency or places with low public transport coverage.

Younger migrants in particular are all well experienced in using their smartphones for organising travel. Hence, they felt comfortable in understanding and using ride-sharing services. This was supported by statements that they usually enjoy ride-sharing and interacting with other people while travelling. The participants highly appreciated that one of the explicit aims of the Fairfahrt system is to bring people together at local/regional level who would otherwise not meet.

As a system like Fairfahrt is free for riders, the service is attractive to refugees who have financial constraints. Hence, they highly value ridesharing solutions for their cost effectiveness. Nevertheless, it was felt that ride-sharing should be seen as a complement of public transport. Being on time for appointments at the authorities, at the doctor's, at school or at work is of utmost importance, due to the constant (perceived or real) threat of losing jobs or being reprimanded in any way. Since it is not guaranteed that a trip request will be answered by a car driver, or may be answered too late, it was argued that it is not reliable enough for certain trip purposes. Finally, 
as one migrant argued, since the service is on a voluntary basis, drivers may reject a rider, which is different to public transport services that are obliged to transport people (given a valid ticket is purchased). This could lead to uncomfortable situations, including acts of racism. However, the refugees highlighted that they had only good experiences with ride-sharing over long distances, such as BlaBlaCar.

\section{Notes}

1 These findings presented here are additional to - but partially overlap with the findings presented in the fieldwork part of this publication, more precisely Chapter 18.

2 The "Together on the move" project focussed on immigrants living in Austria, Belgium and Norway.

3 The central idea of Fairfahrt is that car drivers, on their way to a specific place in Romrod or nearby, can pick up persons at one of five stations and offer them a free ride in their own car. Participating users have to register themselves and receive an ID card allowing them to add a riding request at one of the five stations. The main station is inside a supermarket, the other four are in other districts of the administrative area of Romrod. The drivers, who only need to download the app (and do not necessarily need to register themselves), either receive a push notification or are informed by a green lamp above one of the stations that a ride request has been entered into the system.

\section{References}

AbuJarour, Safa'a, and Hanna Krasnova. 2017. "Understanding the role of ICTS in promoting social inclusion: The case of Syrian refugees in Germany." In Proceedings of the 25th European Conference on Information Systems (ECIS), Guimarães, Portugal, 5-10 June 2017, 1792-1806. http://aisel.aisnet.org/ecis2017_ rp/115. Accessed 2 April 2020.

Alam, Khorshed, and Sophie Imran. 2015. "The digital divide and social inclusion among refugee migrants.” In Information Technology \& People 28, no. 2: 344-365. https://doi.org/10.1108/ITP-04-2014-0083.

Assum, Terje, Tina Panian, Paul Pfaffenbichler, Jan Christiaens, Susanne Nordbakke, Haval Davoody, and Sarah Wixey. 2011. "Immigrants in Europe, their travel behaviour and possibilities for energy efficient travel." http://www.togethereu.org/docs/file/together_d2.1_state-of-the-art.pdf. Accessed 4 February 2020.

Beckman, Jarad D., and Konstadinos G. Goulias. 2008. "Immigration, residential location, car ownership, and commuting behavior: A multivariate latent class analysis from California." In Transportation 35, no. 5: 655-671. http://dx.doi. org/10.1007/s11116-008-9172-x.

Beuret, K., Aslam, H., Gross, A., Osman, A., and F. Khan. 2000. Ethnic Minorities and Visible Religious Minorities: Their Transport Requirements and the Provision of Public Transport. London: Department for Environment, Transport and the Regions.

Blumenberg, Evelyn. 2008. "Immigrants and transport barriers to employment: The case of Southeast Asian welfare recipients in California." In Transport Policy 15, no. 1: 33-42. https://doi.org/10.1016/j.tranpol.2007.10.008. 
Casas, Jesse, Carlos Arce, and Christopher Frye. 2004. "Latino immigration and its impact on future travel behavior." In National Household Travel Survey Conference: Understanding Our Nation's Travel. Washington, DC: Transportation Research Board. http://onlinepubs.trb.org/onlinepubs/archive/conferences/nhts/ Casas.pdf. Accessed 4 February 2020.

Charmarkeh, Houssein. 2013. "Social media usage, Tahriib (migration), and settlement among Somali refugees in France." In Refuge: Canada's Journal on Refugees 29, no. 1: 43-52. https://refuge.journals.yorku.ca/index.php/refuge/article/ view/37505. Accessed 2 April 2020.

Chatman, Daniel G., and Nicholas Klein. 2009. "Immigrants and travel demand in the United States: Implications for transportation policy and future research." In Public Works Management \& Policy 13, no. 4: 312-327. https://doi. org/10.1177/1087724X09334633.

Deakin, Elizabeth, Ferrell, Christopher, Mason, Jonathan, and John Thomas. 2002. "Policies and practices for cost-effective transit investments: Recent experiences in the United States." In Transportation Research Record 1799, no. 1: 1-9. https://doi.org/10.3141/1799-01.

Douma, Frank. 2004. "Using ITS to better serve diverse populations." https:// conservancy.umn.edu/bitstream/handle/11299/1138/200442.pdf?sequence=1. Accessed 4 February 2020.

European Commission. 2016. “EU Immigration Portal Glossary.” https://ec.europa. eu/immigration/glossary_en. Accessed 18 September 2020.

European Union Agency for Fundamental Rights. 2017. "Fundamental Rights Report 2017." https://fra.europa.eu/sites/default/files/fra_uploads/fra-2017-fundamentalrights-report-2017_en.pdf. Accessed 18 September 2020.

Eurostat. 2016. "Urban Europe - statistics on cities, towns and suburbs - foreignborn persons living in cities." https://ec.europa.eu/eurostat/statistics-explained/ index.php?title=Urban_Europe_\%E2\%80\%94_statistics_on_cities, _towns_and_ suburbs_\%E2\%80\%94_foreign-born_persons_living_in_cities\#Foreign-born_ populations_in_predominantly_urban_and_metropolitan_regions. Accessed 10 June 2020.

Eurostat. 2019. "Migration and migrant population statistics." https://ec.europa. eu/eurostat/statistics-explained/index.php?title=Migration_and_migrant_ population_statistics\#Migrant_population:_21.8_million_non-EU-27_citizens_ living_in_the_EU-27_on_1_January_2019. Accessed 10 June 2020.

Eurostat. 2020. "Migration and migrant population statistics - Statistics Explained." https://ec.europa.eu/eurostat/statistics-explained/pdfscache/1275.pdf. Accessed 18 September 2020.

Felton, Emma. 2015. "Migrants, refugees and mobility: How useful are information communication technologies in the first phase of resettlement?" In Journal of Technologies in Society 11, no. 1: 1-13. https://eprints.qut.edu.au/77888/. Accessed 18 September 2020.

Handy, Susan, and Gil Tal. 2005. "The travel behavior of immigrants and race/ ethnicity groups: An analysis of the 2001 national household transportation survey." https://escholarship.org/content/qt4b8382vh/qt4b8382vh.pdf. Accessed 4 February 2020.

Harney, Nicholas. 2013. "Precarity, affect and problem solving with mobile phones by asylum seekers, refugees and migrants in Naples, Italy." In Journal of Refugee Studies 26, no. 4: 541-557. https://doi.org/10.1093/jrs/fet017. 
Kabbar, Eltahir. F., and Barbara J. Crump. 2006. "The factors that influence adoption of ICTs by recent refugee immigrants to New Zealand". In Informing Science 9: 111-121. https://doi.org/10.28945/475.

Kahanec, Martin, Anzelika Zaiceva, and Klaus F. Zimmermann. 2010. "Ethnic minorities in the European Union. An overview." DIW Berlin, German Institute for Economic Research. http://ftp.iza.org/dp5397.pdf. Accessed 2 April 2020.

Klocker, Natascha, Stephanie Toole, Alexander Tindale, and Sophie-May Kerr. 2015. "Ethnically diverse transport behaviours: An Australian perspective." In Geographical Research 53, no. 4: 393-405. https://doi.org/10.1111/1745-5871.12118.

Lovejoy, Kristin, and Susan Handy. 2008. "A case for measuring individuals' access to private-vehicle travel as a matter of degrees: Lessons from focus groups with Mexican immigrants in California.” In Transportation 35, no. 5: 601-612. https:// doi.org/10.1007/s11116-008-9169-5.

Lovejoy, Kristin, and Susan Handy. 2011. "Social networks as a source of privatevehicle transportation: The practice of getting rides and borrowing vehicles among Mexican immigrants in California." In Transportation Research Part A: Policy and Practice 45, no. 4: 248-257. https://doi.org/10.1016/j.tra.2011.01.007.

Myers, Dowell. 1997. "Changes over time in transportation mode for journey to work: Effects of aging and immigration". In Decennial Census Data for Transportation Planning: Case Studies 13: 84.

Purvis, Chuck. 2003. "Commuting patterns of immigrants." CTPP 2000 Status Report, Federal Highway Administration, Bureau of Transportation Statistics, Federal Transit Administration. US Department of Transportation, Washington, DC. http://www.trbcensus.com/newsltr/sr0803.pdf. Accessed 4 February 2020.

Rajé, Fiona. 2007. "The lived experience of transport structure: An exploration of transport's role in people's lives.” In Mobilities 2, no. 1: 51-74. https://doi. org/10.1080/17450100601106260.

Rajé, Fiona. 2017. Negotiating the Transport System: User Contexts, Experiences and Needs. London and New York: Routledge.

Rajé, Fiona, Margaret Grieco, Julian Hine, and John Preston. 2004. Transport, Demand Management and Social Inclusion: The Need for Ethnic Perspectives. Aldershot: Ashgate.

Rosenbloom, Sandra, and G. J. Fielding. 1998. "TCRP Report 28: Transit Markets of the Future: The Challenge of Change." Transit Cooperative Research Program, TRB, National Research Council, Washington, DC. http://onlinepubs.trb.org/ onlinepubs/tcrp/tcrp_rpt_28-a.pdf. Accessed 18 September 2020.

Rutten, Mario, and Sanderien Verstappen. 2014. "Middling migration. Contradictory mobility experiences of Indian youth in London." In Journal of Ethnic and Migration Studies 40, no. 8: 1217-1235. https://doi.org/10.1080/1369183X.2013.830884.

Samek Lodovici, Manuela, and Nicoletta Torchio. 2015. "Social inclusion in EU public transport." Policy Department B: Structural and Cohesion Policies European Parliament. Brussels. http://www.europarl.europa.eu/RegData/etudes/ STUD/2015/540351/IPOL_STU(2015)540351_EN.pdf. Accessed 10 February 2020.

Tal, Gil, and Susan Handy. 2010. "Travel behavior of immigrants: An analysis of the 2001 National Household Transportation Survey." In Transport Policy 17, no. 2: 85-93. https://doi.org/10.1016/j.tranpol.2009.11.003.

Transport for London. 2014. Understanding the Travel Needs of London's Diverse Communities. A Summary of Existing Research. http://content.tfl.gov.uk/ understanding-the-travel-needs-of-london-diverse-communities.pdf. Accessed 13 June 2018. 
Tsang, Flavia, and Charlene Rohr. 2011. The Impact of Migration on Transport and Congestion. Cambridge: RAND Europe.

Uteng, Tanu Priya. 2009. "Gender, ethnicity, and constrained mobility. Insights into the resultant social exclusion." In Environment and Planning A 41, no. 5: 10551071. https://doi.org/10.1068/a40254.

Valenzuela Jr, Abel, Lisa Schweitzer, and Adriele Robles. 2005. "Camionetas: Informal travel among immigrants." In Transportation Research Part A: Policy and Practice 39 no. 10: 895-911. https://doi.org/10.1016/j.tra.2005.02.026. 